\title{
Intentions, Perceptions and Actions Constrain Functional Intra- and Inter- Individual Variability in the Acquisition of Expertise in Individual Sports
}

\author{
Ludovic Seifert ${ }^{*}, 1$ and Keith Davids ${ }^{2}$ \\ ${ }^{1}$ Centre d'Etude des Transformations des Activités Physiques et Sportives (CETAPS) - EA 3832, University of Rouen, \\ Faculty of Sports Sciences, France \\ ${ }^{2}$ School of Human Movement Studies, Queensland University of Technology, Brisbane, Australia
}

\begin{abstract}
Expertise in sport results from the adaptation of behavoirbehavoir to interacting constraints, individually perceived and encountered. With this emphasis on intentionality, perception and action to constrain behavoirbehavoir, the role of movement pattern stability, functional intra-individual and inter-individual performance variability is paramount. Here we illustrate these ideas with reference to two individual performance environments: ice climbing and breaststroke swimming. In ice climbing, compared to beginners, expert climbers exhibited greater levels of variability in upper- and lower-limb coordination patterns, exploring a larger range of limb positions and movement types (ice tool swinging, ice hole hooking). Ice fall properties contain affordances that induced variable motor coordination patterns in expert climbers, whereas learners used a basic and functionally stable motor organization to achieve their main goal of maintaining body equilibrium with respect to gravity. In swimming, while learners organized their limbs to advance in the water, their main intention was to balance, float, breathe, and perceive information. For these reasons they typically adopted one stable (inphase) mode of arm-leg coordination whatever the swim speed. In contrast, experts harnessed available environmental and organismic constraints (strength, flexibility relative to aquatic resistance and the Archimedes principle) to satisfy a key performance constraint (swim fast). To achieve this aim, they varied the arm-leg coordination mode within a stroke cycle and swim speed. Together these data illustrate how functional performance in sport is predicated on the intertwined relationship between intentions, actions and perceptions of each individual, requiring a blend of stable and variable movement patterns to satisfy changing task constraints.
\end{abstract}

Keywords: Movement Pattern Variability, stability, Expertise, Inter-limb coordination, Degeneracy, Adaptability.

\section{INTRODUCTION}

From an ecological dynamics perspective, the intertwined relationship between intentions, perceptions and actions constrains the direction and restrain the range of movement possibilities available for each individual performer. Expertise is the capacity to functionally adapt behavior to satisfy these key constraints in order to achieve performance aims [1]. Beek et al. [2] suggested that the nature of individualenvironment and perception-action coupling is not the same for non-experts and experts, as the expert is more capable of exploiting information about task-related constraints in order to organize behavior. For this reason, the teacher, instructor or coach should provide individual learners with a problem to solve and not a solution to apply in a performance context.

Therefore, the acquisition of expertise requires that learners interact and adapt with the dynamics of the performance environment in real-time. Therefore, while a coordination pattern may be complex to achieve by a learner in sport, more challenging is its functional adaptation to a performance context, i.e., in responding to interacting constraints (task, environmental, or organismic) that continually

*Address correspondence to this author at the CETAPS, University of Rouen, Faculty of Sports Sciences Bld Siegfried, 76821 Mont Saint Aignan Cedex, France; Tel: (33)-2 321077 84; Fax: (33)-2 321077 93;

E-mail: ludovic.seifert@univ-rouen.fr change over time $[1,3]$. The importance of adaptability was originally raised by Bernstein [4] when he conceptualized the notion of resourcefulness (i.e., stability and initiative) as an important property of dexterity (p. 221). In addition to the stabilization of movement patterns, Biryukova and Bril [5] emphasized that a high level of expertise is characterized by motor dexterity, the ability to solve a performance problem quickly, encountered in many different contexts. In other words, dexterity refers to an expert's ability to achieve a task goal correctly, quickly, reasonably (efficiently) and with resourcefulness [4]. Biryukova and Bril [5] concluded that "the dexterity is not movements in themselves, but their ability to adapt to external constraints" (p. 65).

These theoretical ideas suggest that there is no one individual expert pattern of coordination, towards which all developing experts should aspire, but that expertise concerns 'individual-constraint coupling', i.e., expertise in adapting behavior to imposed or perceived constraints and updating these behaviour when constraints change due to changes in intentions, information and actions. Recently, Davids and Glazier [6] postulated that this requisite adaptability was founded on neurobiological system degeneracy, defined as "the ability of elements that are structurally different to perform the same function or yield the same output" (pp. 13763) [7]. They proposed that higher levels of intraindividual movement variability observed in experts could 
play a functional role; for instance, it could correspond to several types of movement and/or to the ability to use coexisting modes of coordination (i.e., exploit multi-stability and meta-stability in complex neurobiological systems; [8]). This relationship between multi-stability and meta-stability in expert performance illustrates the requisite subtle balance needed between stability and variability in sport performance, which arises from the complex interactions between intentions, actions and perceptions of individual performers.

In addition to exploiting information and adapting to different contexts, based on intentions, an important characteristic of expertise in such neurobiological systems is movement pattern variability. Since there is clear evidence that there may be no ideal movement template for learners to imitate during practice [9-11], it follows that movement variability plays a functional role in the acquisition of skill. Traditionally, there has been an overriding tendency to define expertise as the capacity to both reproduce a specific movement pattern consistently and to increase the automaticity of movement. If the central nervous system is assumed to be the organizer and prescriber of motor programs and action plans for an effector system [12-14], when information is identical from one trial to another, then theoretically the response output should also be identical. In the traditional framework, expertise is believed to occur through a reduction in performance deviation by modifying the motor program entry parameters until expert behaviour is achieved. In such representational accounts, movement variability is seen as noise (i.e. an artifact limiting the system's processing of data in-put and out-put) which should be minimized [12-14].

However, research in ecological dynamics has shown that movement system variability is not noise detrimental to performance, error, or deviation from an expert model, which should be corrected in the beginner. Movement system variability instead indicates functional flexibility to respond to dynamic performance constraints [15-20]. Newell and Slifkin [21] indicated that, traditionally, the magnitude of performance variability has been assessed by the standard deviation or variance over trials; these statistical indicators attempt to characterize the data distribution and the amount of noise in a single measurement. The standard deviation measure indicates the magnitude of variability (i.e., the amplitude, the spatial aspect of the distribution of performance over trials), but not the structure of system variability [21]. Instead, studying the temporal structure of variability by spectral analysis of noise provides information on its deterministic or stochastic nature. Newell and Slifkin [19] concluded that it would be wrong to consider that the "deterministic processes specify the invariance of movement and the stochastic processes specify the variance of movement" (p. [21]. In this context, Schöllhorn et al. [10, 11] have even suggested the value of adding noise to the initial conditions of performance to provoke learning by forcing the individual to adapt to varying constraints of the context. Within this framework, there is no ideal motor coordination solution to be repeated, but rather functional patterns of coordination that emerge from the interaction of constraints (task, environmental and organismic) [1, 18, 22, 23] leading to intraindividual and inter-individual movement variability. In previous research, the functional role of movement variability has typically been explored in performance of ball skills (in soccer [24]; in basketball [25, 26]; in volleyball [27]; in handball [28, 29]). Here we extend understanding by exemplifying how intra-individual and inter-individual movement variability could play a functional role in individual physical activities, such as a cyclical movement task (breaststroke swimming) in an aquatic environment and a continuous discrete task (ice climbing) in the wilderness.

\section{INTRA - AND INTER - INDIVIDUAL MOVEMENT PATTERN VARIABILITY IN BREASTSTROKE SWIMMING}

In this section we discuss how the intertwined intentions, perceptions and actions of individuals shape the different coordination patterns assembled during person-environment couplings to achieve a task goal in an aquatic environment. Clearly, task goals will vary between experts (rapid propulsion through the water) and beginners (maintain buoyancy, stability and facilitate breathing) as they attempt to cope in this liquid environment. Since the density of water is about 800 times that of air, aquatic locomotion requires much greater energy expenditure to overcome active drag. Thus, as in breaststroke swimming, the recovery of the arms and legs occurs underwater (in the direction of the swimmer's displacement), and the swimmer encounters high aquatic resistance to the task of organising inter-limb coordination, in order to apply propulsive forces to move forward [30].

In the aquatic environment the human body remains in balance between the Archimedes lift (provided by a buoying force equal to the weight of the water displaced by each learner) and gravitational forces. Coping with these interacting forces in the aquatic environment signifies that the swimmer's focus is not just limited to assembling coordination patterns for propulsion (e.g., moving forward) but also to ensure balance, buoyancy, and breathing. The swimmer must organize the distribution of movement: (i) in water and air over time, and (ii), forward and backward (e.g., the underwater recovery phase/the aquatic propulsion of arms and legs in breaststroke). These interactions of intentions, perception and action for experts and beginners means that breaststroke swimming can be considered a complex multiarticular action for which the management of system degrees of freedom during inter-limb coordination is challenging in different ways.

In expert breaststrokers, one cycle is composed of an alternation of propulsions (i.e., arm propulsion during the leg glide; leg propulsion during the arm glide), a brief glide time with the body fully extended and a synchronization of arm and leg recoveries [31, 32]. In comparison to beginners, during performance, expert breaststrokers show a high level of intra-individual coordination pattern variability, exemplified by a high intra-cyclic knee and elbow angular variability and several modes of arm-leg coordination depending on swim speed [33]. Expert swimmers need to organize different coordination patterns for each performance phase. They display an out-of-phase pattern of coordination of their arms and legs during propulsion (i.e., flexion or extension of a pair of limbs while the other pair of limbs is fixed in extension), an in-phase coordination mode during glide (i.e., extension of the arms and legs) and an anti-phase coordination mode during recoveries (i.e., extension of the arms during 
leg flexion) [33, 34]. In a cycle of 1.5 to $2 \mathrm{~s}$, expert swimmers are able to alternate between these three modes of coordination (Fig. 1).

Clearly, expert swimmers need to show high levels of inter-limb coordination flexibility, as they attempt to harness three modes of coordination to vary swim speed, depending on their intentions. At slow speeds, they can insert a glide time of varying length, shifting their arm-leg coordination between a "glide" mode (e.g., at slow paces) and a "continuous" mode (e.g., at mid-distance paces). The term "continuous" signifies that arm propulsion follows leg propulsion (i.e., no glide phase). At sprint pace, expert breaststrokers use a "superposition" coordination mode where the beginning of the leg propulsion overlaps the end of the arm recovery in order to maintain high average swim velocity [32, 35]. It is interesting to note that this superposition mode, in which the body forms an " $\mathrm{X}$ ", is commonly observed in the recreational swimmer who uses it regardless of swimming speed
[33, 36]. Finally, expert swimmers typically display low inter-individual variability in coordination patterns, when they need to maintain movement pattern stability in the aquatic environment (Fig. 2) [37]. These data on skilled behaviour illustrate that an 'optimal' movement template is not the same as a stable movement pattern (which can be relied upon for performance, but which can be adapted to changing constraints). This characteristic of expertise is predicated on the qualities of multi-stability and meta-stability in expert movement systems [38].

In contrast, due to their different mix of intentions, perceptions and actions, learners show low intra-individual coordination variability, but very high inter-individual coordination variability (Fig. 2), notably a bi-stability of the armleg coordination modes that could lead to several intermediate profiles. A primary constraint on beginners is the need to maintain stability in the water in order to breathe and not sink, and the first coordination mode corresponds to an iso-

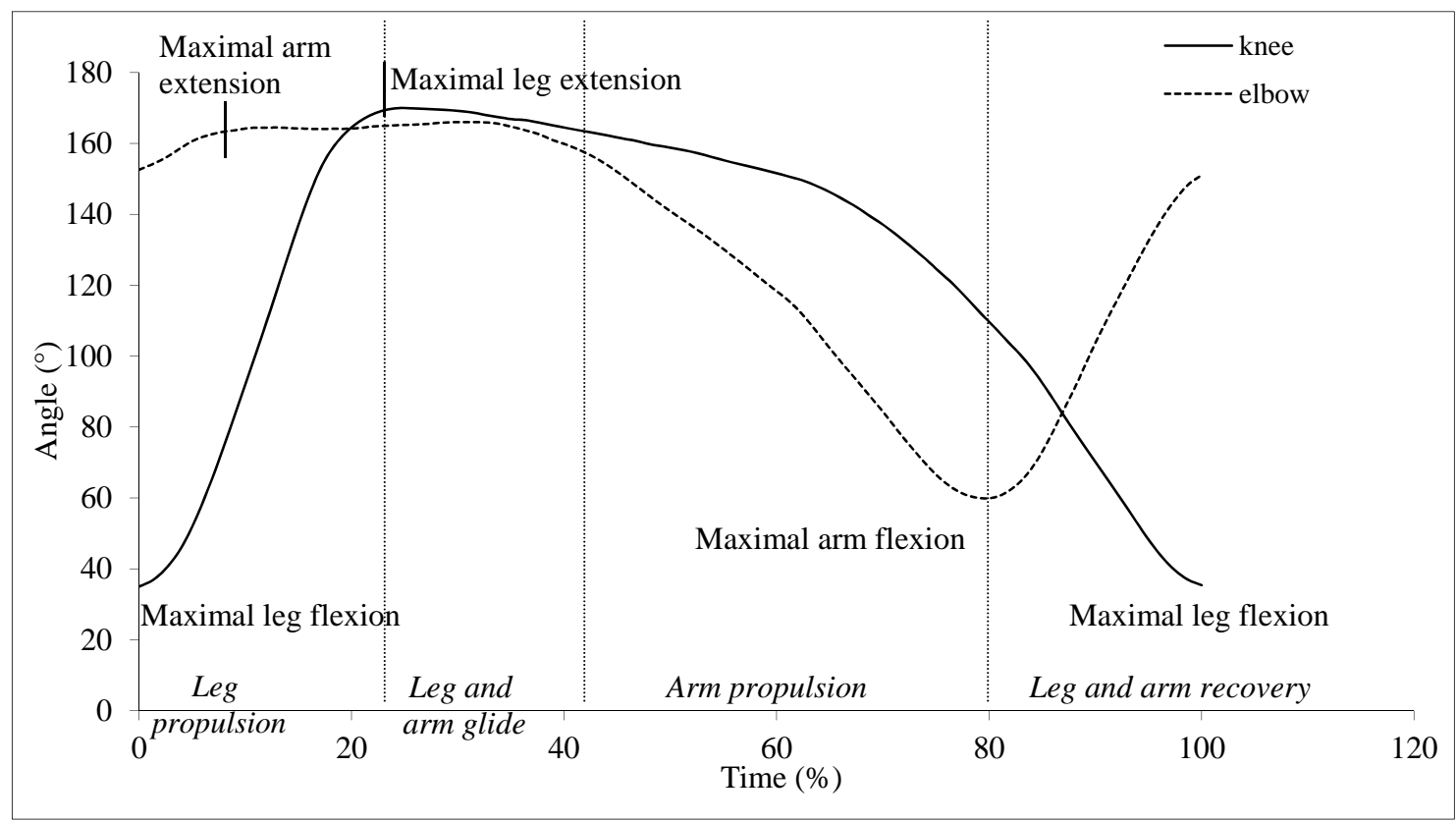

Fig. (1). Knee and elbow angular position through one complete cycle for an expert breaststroke swimmer (adapted from [33]).
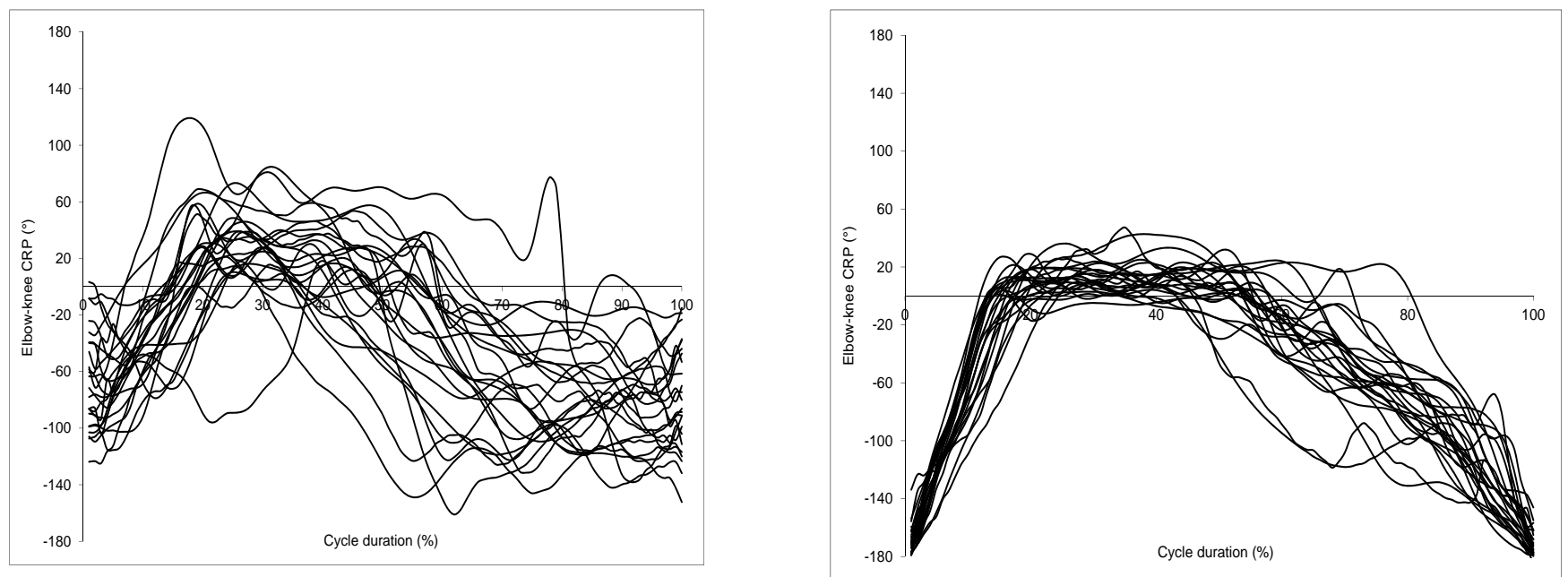

Fig. (2). Continuous relative phase (CRP) between elbow and knee through a complete cycle for 24 beginners (left panel) and for 24 expert swimmers (right panel), showing lower inter-individual variability for experts. 
contraction of the non-homologous limbs: that is, the inphase muscle contraction of the arms and legs [39-41]. One way to enhance system stability is to synchronize the flexion movements of both arms and legs, as well as the extension movements [42] like an "accordion", supporting emergence of low intra-cyclic arm-leg coordination variability (Fig. 3). The accordion mode of coordination corresponds to a superposition of two contradictory actions [33, 34, 36]: leg propulsion during arm recovery and arm propulsion during leg recovery. It is not mechanically effective and does not provide high swim speed because each propulsive action is thwarted by a recovery action. As observed in other studies of inter-limb coordination, this coordination mode appears to be the most stable and the easiest to perform for learners (for evidence in bi-manual coordination see [43]; hand-foot tasks, see [44, 45]; lower leg transitions, see [46]). This superposition of arm and leg actions may be partial and occurs at two moments in the cycle: the end of arm propulsion can overlap the beginning of the leg recovery and the beginning of leg propulsion can overlap the end of the arm recovery [33, 35].

The second mode of coordination observed in beginners is the flexion movement of one set of limbs that occurs during the extension of the other set, following the principle of iso-direction, which consists of making movements in the same direction (e.g., arms and legs go forward or backward on the longitudinal axis) [39, 40, 41]. This arm-leg coordination corresponds to a superposition of the propulsive phases of the arms and legs. When the superposition of these two propulsions is complete, the arm-leg coordination pattern resembles the movements of "windscreen wipers" and shows low intra-cyclic coordination variability. If there is no glide time of the legs, the "windscreen wipers" movement can affect the recovery phase, so that the arm and leg recoveries are completely superposed, which is recommended to minimize forward resistance. This superposition of propulsive forces can be partial. In this case, the body is in an " $\mathrm{X}$ " position with arms and legs in complete extension. Finally, although there is bi-stability in the modes of arm-leg coordination of beginning breaststroke swimmers, several combinations of these two modes of coordination may arise for a variety of reasons, illustrating functional inter-individual variability [47]. Although the windscreen wipers and the accordion modes of coordination are inefficient, they emerge from the interactions of the intentions, perceptions and actions of learners in response to the need for system stability in an aquatic environment. The comparison of data from beginners and experts in the breaststroke showed how the specific nature of the task goals interact with emergent coordination tendencies to shape the stability and variability of movement patterns harnessed by each individual. From a constraint-led approach, the emergent behavior of learners are understandable, because they relate to the over-arching need for maintaining buoyancy, stability and breathing capacity in aquatic environments. These suggestions were supported by a cluster analysis of the movement patterns of 24 beginning swimmers [47]. The emergent movement patterns were: (i) stable coordination modes, based on principles of iso-contraction and/or iso-direction [39, 40, 41], (ii) indicative of beginners in an exploratory phase with regard to environmental constraints, and (iii), the task constraint or goal of the action "propel the body forward and fast" imposed by the teacher or coach was perceived differently by beginners because their priority was not just to move forward in the water, but also to balance (e.g., to stay in a ventral position), float (e.g., to stay at the water surface) and breathe (e.g., to avoid bringing hands to the chest in order to keep the head above water) to see in the aquatic environment. This rich mix of intentions, perceptions and actions explain the great inter-individual coordination variability in beginners, providing evidence for neurobiological system degeneracy. Even if the movement pattern of beginners is neither efficient, nor effective because of its inherent stability in freezing system degrees of freedom, nevertheless they were still able to exploit system degeneracy to explore different functional movements.

In summary, these comparisons between the movement patterns of beginners and expert swimmers reveal the influence of different intentional constraints. They pose the questions: (i) whether beginners should be encouraged to imitate expert swimmers, and (ii), whether coordination patterns observed in beginning swimmers should be considered as 'errorful' simply because they differ from a putative ideal movement model based on an analysis of expert swimmers. A novice's movement pattern may actually reflect a different

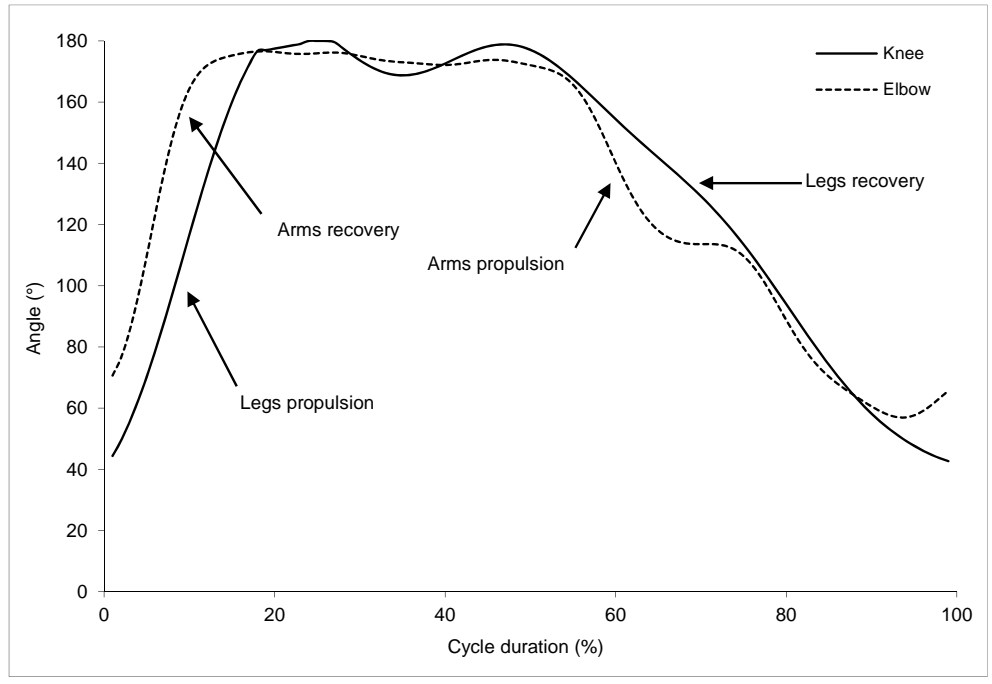

Fig. (3). Knee and elbow angular position through one complete cycle for a learner in swimming (adapted from [47]). 
performance priorities based on a mix of intentions, perceptions and actions, compared to an expert (i.e. in swimming to maintain buoyancy, rather than the intention of advancing rapidly through the water).

\section{INTRA-INDIVIDUAL COORDINATION PATTERN VARIABILITY IN ICE CLIMBING}

How intentions, actions and perception of information guide movement pattern formation in individuals interacting with their performance environments, regardless of skill level, has also been shown in studies of ice climbers. Ice climbing involves climbing with ice tools in each hand and crampons on each foot on frozen water falls, the properties of which vary stochastically in shape, steepness, temperature, thickness and ice density. Since these environmental constraints are not predictable and under the control of the climber, this task requires successful climbers to utilise numerous types of movements (e.g., swinging, kicking and hooking actions) and patterns of inter-limb coordination (e.g., horizontal-, diagonally- and vertical-located angular positions) during performance by exploiting complex neurobiological system properties of degeneracy and multistability. For instance, climbers could either swing their ice tools to create their own holes or hook an existing hole (due to the actions of previous climbers or by exploiting the presence of natural holes), supporting the functional role of intraindividual variability. In our study of ice climbing we examined performance of beginners and skilled climbers as they climbed a frozen waterfall. We assessed inter-limb coordination patterns by using the angle between the horizontal line and the displacement of the heads of the left and right hand ice tools for the upper limb coordination. Lower limb coordination patterns corresponded to the angle between the hor- izontal line and the displacement of the left and right crampons (Fig. 4) [48].

When both groups of climber climb an ice fall with a quasi vertical slope (range between 80 to $90^{\circ}$ ), beginners showed low levels of intra-individual movement and interlimb coordination variability, as they varied their upper limb- and lower limb-coordination patterns much less frequently and extensively than the experts. Note that 'movement' refers to the type of actions, such as ice tool swinging and hooking, while 'inter-limb coordination' refers to angular limb positions, such as horizontally, diagonally, verticallylocation. As in the study of the novice breaststroke swimmers, we observed patterns of movement which were indicative of the intentions idiosyncratic to this group. Their actions differed considerably from those of expert ice climbers. Beginners mostly used horizontally- and diagonally-located angular positions (since limb anchorages are at the same level for the horizontal angle, the arms or legs appear in an in-phase coordination mode). This highly stable behaviour resembled climbing up a ladder and led them to maintain a static " $X$ " body position with arms and legs extended or with arms flexed and legs extended, corresponding to a freezing of the motor system degrees of freedom. Due to their lack of attunement to information from properties of the ice fall, beginners tended not to hook the ice tool into existing holes in the ice fall but tended to swing the ice tool into or out of the holes. Due to their great need for stability, beginners mainly focused on attaining a deep anchorage on the ice fall for both ice tools and crampons, by using lots of ice tool swinging and crampon kicking, suggesting that icefall properties (e.g., shape, steepness, temperature, thickness and ice density) were not perceived by them as relevant affordances for action. As observed in a repetitive hammering task [49],
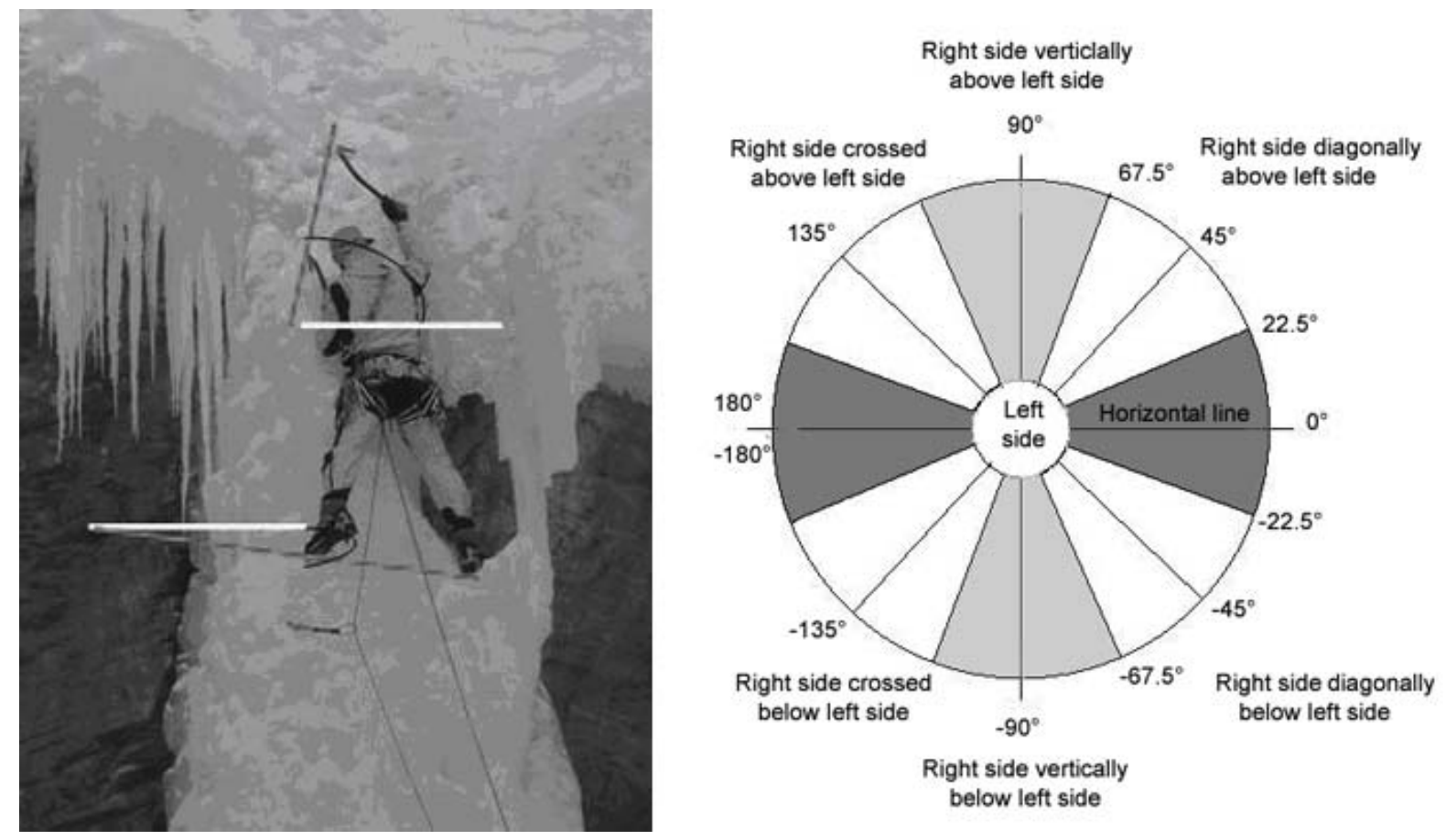

Fig. (4). Angle between horizontal, left limb and right limb (left panel). Modes of limbs coordination as regards the angle value between horizontal, left limb and right limb (right panel). The angle between the horizontal line and the left and right limbs was positive when the right limb was above the left limb and negative when the right limb was below the left limb. 
although this behaviour might enhance their stability on the ice fall, it also led to greater levels of fatigue. Like the novice breaststrokers, the novice ice climbers tended to prioritize stability and security of posture in interacting with environmental constraints, rather than speed and efficiency of movement.

Conversely, expert ice climbers showed high intraindividual movement and coordination pattern variability, supporting an efficient balance between dependency/independency of their actions from the environment as they exploited affordances in the specific ice fall properties. The efficient individual-environment coupling of the experts was likely predicated on neurobiological system degeneracy [6, 7] since they varied the types of movement and the interlimb coordination modes they exploited to achieve their task goals. Indeed, the multi-stability of their complex movement systems allowed them: (i) to swing the ice tools and to kick the crampons in many different ways: in horizontal, diagonal, vertical and crossed angular positions, exploiting the functionality of intra-individual movement pattern variability. For instance, crossing the arms is not a natural action, but it enabled experts to exploit information and hook existing holes in the ice fall; and (ii), to hook the ice tools into already existing holes (i.e. exploiting information on the shape of the ice fall) and to place the crampons in the holes previously made by their own ice tools, instead of using repetitive ice tool swinging and crampon kicking as observed in beginners.

Compared to the intentions and actions of expert performers (i.e., climb as fast as possible or travel a great distance between each anchorage), the static quadripodal position of the beginners could appear as errorful because the long time spent in isometric muscular contraction would come at a high energy cost. However, in understanding the interactions of intentionality, action and perception, these emergent behavoir were understandable. As in swimming, an individual's behavoir relate to differentiated intentions and perception of the task and environmental constraints. Notably, the beginners were functioning independently of the ice fall's properties, because they were mainly focusing on keeping their equilibrium, with respect to gravity, under control. These observations suggest that manipulation task constraints by a coach or teacher would enable the beginners to further interact with the icefall properties in a secure learning environment, in order to balance their independency/dependency to the environmental constraints, and to gradually support the emergence of a wider repertoire of movement and multi-stability of coordination patterns.

\section{THE CONSTRAINTS-LED APPROACH IN PRAC- TICE}

The findings of the studies of swimming and climbing highlight a functional role of intra- and inter-individual coordination patterns variability. From a pedagogical perspective, an ecological dynamics framework highlights a constraints-led approach, which consists of the manipulation of constraints on individuals during practice to encourage functional behavoir to emerge. This approach assumes that there is no ideal or expert behaviour to imitate [9, 37, 50], but that a response emerges from interacting constraints of inten- tions, actions and perceptions. So a response would be individual and not conform to an ideal performance template predefined by the coach or teacher, supporting a non-linear acquisition of expertise [51]. In a constraints-led approach, learning is highly oriented to each learner and based on an individual's capacity (organismic constraints) throughout a learning programme, leading some authors to characterize this approach as developmental [52-54]. From this perspective, a teacher or coach is seen as a manipulator of constraints to influence, provoke and stimulate functional behavoir from each individual, which requires that the sport activities taught are familiar so that the task constraints can be easily manipulated [55]. For example, a hydrodynamic (buoyant and secure) position in swimming could be learned by pulling a beginning swimmer with a rubber band or a pole to provide stability in the water and amplify swim speed (environmental constraint). This temporary support would be geared towards helping the learner to discover how to satisfy the informational and task constraints at an early stage through exploratory practice. In ice climbing, a variety of movement patterns (e.g., hook, swing, kick) and limb coordination patterns (e.g., vertical angular position of ice tools) could be learned by focusing the beginner on information offered by environment (e.g., existing holes in the icefall created by the previous climber or holes made by the ice tools that could be used for crampons).

Moreover, to enable a functional role of movement variability, the acquisition of expertise should be more implicit in the sense of not geared towards prescriptive teaching of putative expert templates to all learners, regardless of their needs [23, 55-58]. Rather the aim of a constraints-led approach is to lead the learner to explore, discover, and interact with the task and environmental constraints, without referring to explicit memories of movements, to encourage a greater focus on adaptive, exploratory, emergent interactions with changing environmental and task constraints. This aim could be achieved by emphasising the role of knowledge of the environment that would be useful to support acting in the performance context. Learning is implicit because the teacher provides information mainly on the task goal, the "what to do?" rather than on the process and procedures, the "how to do?", leaving the learner to achieve his or her own functional movement solution in a non-linear way, to encourage adaptive variability and exploit fluctuations and transitions during performance. The coach or the teacher gives the learner a performance problem to solve instead of a prescribed movement solution to imitate.

For instance, in ice climbing, the coach could instruct the learner to use the steps and the holes in the icefall, in order to focus the individual on the icefall properties rather than imposing a theoretical pattern of coordination (e.g., use a vertical angular position of the ice tools) that will not help the climber to interact with his environment. In this way, the individual can discover that holes in the icefall can be hooked, or to make the blade anchorage better, the holes can be swung into by the ice tool. The coach or the teacher gives the learner a margin of freedom in the movement organization, he/she only needs to specify the global behaviour to be adopted by using analogies, defined as "biomechanical metaphors" $[23,56,59,60]$. In this context, the teacher who is teaching the learner to maintain a hydrodynamic position in 
swimming may use analogies such as "glide like a torpedo" or "glide like Superman"; these instructions allow the learner to explore the different possibilities for being hydrodynamic in the water rather than listening to verbal explanations on exactly how to place the hands, arms, and head when he or she he may not have the flexibility to adopt such a position. This recommendation is particularly useful in learning the breaststroke to aid the emergence of a specific glide time (e.g., after the arms recovery or after the legs propulsion) instead of explaining step by step the different stroke phases and limbs position and coordination. This vision of skill acquisition breaks with the traditional view of explicit learning and coaching, where the teacher or the coach gives a series of verbal instructions on each parameter of the movement to learn and to correct. These verbal instructions constitute declarative and procedural knowledge about the environment that the individual is required to store in memory and mobilize for action [61].

In summary, based on an ecological dynamics framework, we reviewed experimental data justifying a rationale non-linear approach of skill acquisition in individual activities like swimming and climbing. These data contribute to the extant literature which has mainly focused on the acquisition of ball skills. We emphasized the functional role of intra- and inter-individual movement variability as the individuals were able to show behavioural adaptability (intentions), flexibility (perception of different information sources), multi-stability coordination patterns and neurobiological degeneracy (to mix stable and variable actions) in satisfy interacting constraints. These characteristics of dynamical movement systems provide evidence for the use of a constraints-led approach to encourage emergent adaptive behavoir in practice.

\section{CONFLICT OF INTEREST}

The authors confirm that this article content has no conflicts of interest.

\section{ACKNOWLEDGEMENT}

There was no conflict of interest for this project which received the funding of the CPER/GRR1880 Logistic Transport and Information Treatment 2007-2013.

\section{REFERENCES}

[1] Newell KM. Constraints on the development of coordination. In: Wade MG, Whiting HTA, Ed. Motor development in children: aspect of coordination and control, Dordrecht, Nijhoff 1986; pp. 341-60.

[2] Beek PJ, Jacobs D, Daffershofer A, Huys R. Expert performance in sport: views from the joint perspections of ecological psychology and dynamical systems theory. In: Starkes JL, Ericsson KA, Ed. Expert performance in sports. Champaign Illinois: Human Kinetics Publishers 2003; pp. 321-42.

[3] Guerin S, Kunkle D. Emergence of constraint in self-organized systems. Nonlinear Dyn Psychol Life Sci 2004; 8: 131-46.

[4] Bernstein NA. Dexterity and its development. In: Latash ML, Turvey MT, Ed. Dexterity and its development. Mahwah, New Jersey: Lawrence Erlbaum Associates Publishers 1996; pp.1-235.

[5] Biryukova E, Bril B. Bernstein et le geste technique. Revue d'anthropologie des connaissances 2002; 2: 49-68.

[6] Davids K, Glazier P. Deconstructing neurobiological coordination: the role of the biomechanics-motor control nexus. Exerc Sport Sci Rev 2010; 38: 86-90.
[7] Edelman GM, Gally JA. Degeneracy and complexity in biological systems. Proc Natl Acad Sci USA 2001; 98: 13763-8.

[8] Kelso JAS. Dynamic patterns: the self-organization of brain and behaviour. Cambridge: MIT Press 1995.

[9] Brisson TA, Alain C. Should common optimal movement patterns be identified as the criterion to be achieved? J Mot Behav 1996; 28: 211-23.

[10] Schöllhorn WI, Beckmann H, Janssen D, Drepper J. Stochastic perturbations in athletics field events enhance skill acquisition. In: Renshaw I, Davids K, Savelsbergh GSP, Eds. Motor learning in practice: A constraints-led approach. New York: Routledge 2010; pp. 69-82.

[11] Schöllhorn WI, Mayer-Kress G, Newell KM, Michelbrink M. Time scales of adaptive behavior and motor learning in the presence of stochastic perturbations. Hum Mov Sci 2009; 28: 319-33.

[12] Summers JJ, Anson JG. Current status of the motor program: revisited. Hum Mov Sci 2009; 28: 566-77.

[13] Johnson-Laird PN. Mental models: towards a cognitive science of language, inference and consciousness. Cambridge, UK: Cambridge University Press 1983.

[14] Schmidt R, Lee T. Motor control and learning: A behavioral emphasis. $5^{\text {th }}$ ed. Champaing Illinois: Human Kinetics 2011.

[15] Bartlett R, Wheat J, Robins M. Is movement variability important for sports biomechanists ? Sports Biomech 2007; 6: 224-43.

[16] Davids K, Glazier P, Araújo D, Bartlett R. Movement systems as dynamical systems, the functional role of variability and its implications for sports medicine. Sports Med 2003; 33: 245-60.

[17] Davids K, Bennett S, Newell K. Movement system variability. Champaign, Illinois: Human Kinetics 2006.

[18] Glazier PS, Davids K. Constraints on the complete optimization of human motion. Sports Med 2009; 39: 15-28.

[19] Newell KM, Corcos DM. Issues in variability and motor control. In: Newell KM, Corcos DM, Eds. Variability and motor control, Champaign, Illinois: Human Kinetics Publishers 1993; pp.1-12.

[20] Riley MA, Turvey MT. Variability and determinism in motor behavior. J Mot Behav 2002; 34: 99-125.

[21] Newell KM, Slifkin AB. The nature of movement variability. In: Piek JP, Ed. Motor behaviour and human skill: A multidisciplinarity perspective. Champaign, Illinois: Human Kinetics Publishers 1998; pp.143-60.

[22] Davids K, Araujo D, Shuttleworth R, Button C. Acquiring skill in sport: a constraints-led perspective. Int J Comput Sci Sport 2004; 2: 31-9.

[23] Davids K, Button C, Bennett S. Dynamics of skill acquisition: a constraints-led approach. Champaign, Illinois: Human Kinetics 2008.

[24] Chow JY, Davids K, Button C, Koh M. Variation in coordination of a discrete multiarticular action as a function of skill level. J Mot Behav 2007; 39: 463-79.

[25] Button C, Mac Leod M, Sanders R, Coleman S. Examining movement variability in the basketball free-throw action at different skill levels. Res Quart Exerc Sport 2003; 74: 257-69.

[26] Rein R, Davids K, Button C. Adaptive and phase transition behavior in performance of discrete multi-articular actions by degenerate neurobiological systems. Exp Br Res 2010; 201: 30722.

[27] Davids K, Bennett S, Handford C, Jones B. Acquiring coordination in self-paced extrinsic timing tasks: a constraints led perspective. Int J Sport Psychol 1999; 30: 437-61.

[28] Fradet L, Botcazou M, Durocher C, et al. Do handball throws always exhibit a proximal-to-distal segmental sequence? J Sports Sci 2004; 22: 439-47.

[29] Schorer J, Baker J, Fath F, Jaitner T. Identification of interindividual and intraindividual movement patterns in handball players of varying expertise levels. J Mot Behav 2007; 39: 409-21.

[30] Toussaint HM, Truijens M. Biomechanical aspects of peak performance in human swimming. Anim Biol 2005; 55: 17-40.

[31] Chollet D, Seifert L, Leblanc H, Boulesteix L, Carter M. Evaluation of the arm-leg coordination in flat breaststroke. Int $\mathrm{J}$ Sport Med 2004; 25: 486-95.

[32] Seifert L, Chollet D. A new index of flat breaststroke propulsion: a comparison between elite men and elite women. J Sports Sci 2005; 23: 309-20.

[33] Seifert L, Leblanc $H$, Chollet $D$, Delignières D. Inter-limb coordination in swimming: effect of speed and skill level. Hum Mov Sci 2010; 29: 103-13. 
[34] Seifert L, Chollet D. Inter-limb coordination and constraints in swimming: a review. In: Beaulieu NP, Ed. Physical activity and children: new research. Hauppauge, New York: Nova Science Publishers 2008; pp. 65-93.

[35] Leblanc H, Seifert L, Baudry L, Chollet D. Arm-leg coordination in flat breaststroke : a comparative study between elite and non-elite swimmers. Int J Sports Med 2005; 26: 787-97.

[36] Leblanc H, Seifert L, Chollet D. Arm-leg coordination in recreational and competitive breaststroke swimmers. J Sci Med Sport 2009; 12: 352-56.

[37] Seifert L, Button C, Brazier T. Interacting constraints and coordination in swimming. In: Renshaw I, Davids K, Savelsbergh GJP, Eds. Motor learning in practice: A constraints-led approach. London: Routledge 2010; pp. 83-98.

[38] Davids K, Araújo D, Hristovski R, Passos P, Chow JY. Ecological dynamics and motor learning design in sport. In: Williams AM, Hodges N, Eds. Skill Acquisition in Sport: Research, Theory \& Practice, $2^{\text {nd }}$ ed. London: Routledge (in press).

[39] Baldissera F, Cavalleri P, Civaschi P. Preferential coupling between voluntary movements of ipsilateral limbs. Neurosci Lett 1982; 74: 95-100.

[40] Baldissera F, Cavalleri P, Marini G, Tassone G. Differential control of in-phase and anti-phase coupling of rhythmic movements of ipsilateral hand and foot. Exp Brain Res 1991; 83: 375-80.

[41] Swinnen SP, Jardin K, Meulenbroek R, Douskaia N, Hofkens-Van Den Brandt R. Egocentric and allocentric constraints in the expression of patterns of inter-limb coordination. J Cogn Neuro 1997; 9: 348-77.

[42] Tokuyama H, Okamoto T, Kumamoto M. Electromyographic study of swimming in infants and children. In: Komi PV, Ed. Biomechanics V-B., International Series on Biomechanics, vol. IB. Baltimore: University Park Press 1976; pp. 215-21.

[43] Kelso JAS. Phase transitions and critical behavior in human bimanual coordination. Am J Physiol Regul Integ Comp Physiol 1984; 15: R 1000- 4.

[44] Jeka JJ, Kelso JAS, Kiemel T. Pattern switching in human multilimb coordination dynamics. Bull Math Biol 1993; 55: 82945.

[45] Kelso JAS, Jeka JJ. Symmetry breaking dynamics of human multilimb coordination. J Exp Psychol: Hum Percept Perf 1992; 18: 64568.

[46] Diedrich FJ, Warren WH. Why change gaits? Dynamics of the walk-run transition. J Exp Psychol: Hum Percept Perf 1995; 21: 183-202.

[47] Seifert L, Leblanc H, Herault R, Button C, Komar J, Chollet D. Inter-subject variability in the upper-lower limb breaststroke coordination. Hum Mov Sci 2011; 30: 550-65.
[48] Seifert L, Wattebled L, L’Hermette M, Hérault R. Inter-limb coordination variability in ice climbers of different skill level. Educ Phys Train Sport 2011; 1: 63-8.

[49] Côté JN, Feldman AG, Mathieu PA, Levin MF. Effects of fatigue on intermuscular coordination during repetitive hammering. Mot Control 2008; 12: 79-92.

[50] Chow JY, Davids K, Button C, Shuttleworth R, Renshaw I, Araùjo D. Nonlinear pedagogy: a constraints-led framework for understanding emergence of game play and movement skills. Nonlinear Dynamics Psychol Life Sci 2006; 10: 71-103.

[51] Chow JY, Davids K, Hristovski R, Araújo D, Passos P. Nonlinear pedagogy: learning design for self-organizing neurobiological systems. New Ideas Psychol 2011; 29: 189-200.

[52] Lagendorfer SJ. The developmental perspective, the swimming reflex, and the velveteen rabbit. Int J Aquat Res Educ 2005; 1: 2.

[53] Lagendorfer SJ. Applying a developmental perspective to aquatics and swimming. In: Kjendlie PL, Stallman R, Cabri J, Eds. Biomechanics and Medicine in Swimming XI. Oslo: University of Oslo, Norway 2010; pp. 20-2.

[54] Stodden DF, Goodway JD, Langendorfer SJ, et al. A developmental perspective on the role of motor skill competence in physical activity: an emergent relationship. Quest 2008; 60: 290306.

[55] Davids K. The constraints-based approach to motor learning: Implications for a nonlinear pedagogy in sport and physical education. In: Renshaw I, Davids K, Savelsbergh GJP, Eds. Motor learning in practice: A constraints-led approach. New York: Routledge 2010; pp. 3-16.

[56] Masters RSW. Theoretical aspects of implicit learning in sport. Int J Sport Psychol 2000; 31: 530-41.

[57] Masters RSW, Maxwell JP. Implicit motor learning, reinvestment and movement disruption: What you don't know won't hurt you. In: Williams AM, Hodges NJ, Eds. Skill acquisition: research, theory and practice. New York: Routledge 2004; pp. 207-28.

[58] Masters RSW, Poolton JM, Maxwell JP, Raab M. Implicit motor learning and complex decision making in time-constrained environments. J Mot Behav 2008; 40: 71-9.

[59] Lam WK, Maxwell JP, Masters RSW. Analogy learning and the performance of motor skills under pressure. J Sport Exer Psychol 2009; 31: 337-57.

[60] Liao C, Masters RSW. Analogy learning: A means to implicit motor learning. J Sports Sci 2001; 19: 307-19.

[61] Maxwell JP, Masters RS, Eves FF. The role of working memory in motor learning and performance. Consc Cogn 2003; 12: 376-402.

Received: July 12, 2011

Revised: May 25, 2012

Accepted: May 30, 2012

(C) Seifert and Davids; Licensee Bentham Open.

This is an open access article licensed under the terms of the Creative Commons Attribution Non-Commercial License (http://creativecommons.org/licenses/ by-nc/3.0/) which permits unrestricted, non-commercial use, distribution and reproduction in any medium, provided the work is properly cited. 